\title{
Cardiopulmonary Resuscitation Knowledge among Physiotherapy Students in Ahmedabad
}

\author{
Jalpakunvarba Prabhatsinh Chauhan ${ }^{1}$, Hemal Patel ${ }^{2}$ \\ ${ }^{1}$ Second Year MPT Student, JG College of Physiotherapy, Ahmedabad. \\ ${ }^{2}$ PG Guide \& Lecturer, JG College of Physiotherapy, Ahmedabad. \\ Corresponding Author: Jalpakunvarba Prabhatsinh Chauhan
}

DOI: https://doi.org/10.52403/ijhsr.20220308

\begin{abstract}
Background: Cardiopulmonary resuscitation reduces cardiac arrests and associated deaths when patients receive prompt CPR from trained healthcare professionals. Physiotherapists, using exercise as a therapeutic approach, need to have good CPR knowledge and skills not only to deal with possible adverse cardiac events during exercise but also because the widespread application of CPR and early defibrillation can significantly reduce mortality from a heart attack. In this study, we assessed cardiopulmonary resuscitation knowledge among physiotherapy students in Ahmedabad.

Aims and Objective: This study aimed to assess CPR knowledge among physiotherapy students in Ahmedabad.

Method: A cross-sectional study of physiotherapy students in Ahmedabad was conducted. An online survey was conducted with a self-administered questionnaire. The data was collected from 191 physiotherapy students in Ahmedabad aged 18-25 years. A CPR knowledge questionnaire was completed by the students and the result was analyzed with Microsoft Excel 2019.

Results: Our results suggest that the students were a good understanding of the importance of CPR in clinical practice and stand average in knowing its indications and effectiveness. Whereas, only $4.18 \%$ of them were completely aware of the universal compression ventilation ratio, and $38.21 \%$ were aware of the current order of CPR being compression, airway, and breathing.

Conclusion: In our study, we concluded that awareness of CPR is good among physiotherapy students in Ahmedabad.
\end{abstract}

Key Words: Cardiopulmonary resuscitation knowledge, Physiotherapy Students, Awareness of CPR.

\section{INTRODUCTION}

Cardiovascular disease (CVD) has become the leading cause of death in India. This epidemiological transition is significant due to the increased prevalence of CVD and CVD risk factors in India. India has one of the highest cardiovascular diseases (CVD) burdens in the world. The annual number of CVD deaths in India is expected to increase from 2.26 million (1990) to 4.77 million (2020). The Prevalence rates of coronary heart disease in India have been estimated over the past decades and ranged from $1.6 \%$ to $7.4 \%$ in rural populations and $1 \%$ to $13.2 \%$ in urban populations.
Cardiac arrest (also called cardiorespiratory arrest or circulatory arrest) is the cessation of normal blood flow due to the heart's inability to contract effectively. [1] Sudden cardiac arrest (SCA) is a medical emergency. If not treated immediately, it causes sudden cardiac death. With prompt and appropriate medical treatment, survival is possible. An (SCA) is classified as in hospital and out of the hospital.

Cardiopulmonary resuscitation (CPR) is an evolving lifesaving technique in modern medicine that includes a series of lifesaving actions that improve survival 
rates after SCAs. Some studies have shown that immediate CPR after collapse due to ventricular fibrillation doubles and even triples the chances of survival. Conversely, the chance of survival decreases by $7 \%$ to $10 \%$ for each minute of delayed CPR.[2]

Physiotherapists, using exercise as a therapeutic approach, must have good knowledge and skills in CPR not only to deal with possible adverse cardiac events during exercise but also because the widespread application of CPR is early defibrillation can significantly reduce cardiac mortality [3] CPR is the technique for delivering basic life support (BLS) until advanced life support (ALS) can be delivered or circulation is restored and spontaneous ventilation. [4]

A physiotherapist is a medical professional who can work in an intensive and critical care facility and manage who should be able to treat heart disease even though exercising in places like this requires knowledge of CPR, so it is important to assess these professionals' knowledge on this subject to support curricular revisions and continuing education that will equip physiotherapists to improve patient.

\section{METHOD}

Data of 191 Physiotherapy students (UG and PG) of Ahmedabad was collected. A cross-sectional study was conducted. A questionnaire was administered and spread through Google forms. The link of the CPR questionnaire was sent through WhatsApp and other social media and the link was also Forwarded to students apart from the first point of contact and so on. After they accepted to take the survey, they filled up the demographic details and several questions related to CPR knowledge.

Participating students aged was 18 to 25 years and both male and female participants were included who were able to understand English, and those who were willing to participate were included. If students are not willing to participate at any point in the survey and do not want to continue to cooperate, they will be excluded from the study.

The CPR Knowledge Questionnaire was used. The questionnaire consisted of three parts, the first with general questions about the importance of CPR in clinical practice, the second with questions about the main objective and precision of CPR interventions, and the last segment consisting of questions about the indications, methods, and effectiveness of CPR. The total of correctly answered questions in each category was counted and scored. The total scores for each category were converted into percentages and divided into preset ratings as follows: $>60 \%$ Excellent, 40-60\% Good, and $<40 \%$ Poor.191 Responses were collected within two months. The knowledge questionnaire on cardiopulmonary resuscitation was evaluated and interpreted. The analysis was carried out with Microsoft Excel 2019.

\section{RESULTS}

Overall, 191 students have participated. Among three categories of a questionnaire survey, students were excellent $(94.76 \%$ reciprocated with positive response) in the first one regarding the importance of CPR where they gave more collective positive response on knowledge and need of CPR. The negatively framed question "CPR was harmful" was intelligently understated by $79.05 \%$ of students. However, $14.13 \%$ of them differed by saying "did not know" and $6.80 \%$ has unfortunately accepted the statement [Table/Fig-1].

In the second category, questions chosen were about the main goal and accuracy of CPR intervention (in terms of scores rewarded, $18.3 \%$ of them graded as excellent, $39.7 \%$ scored as good and $43 \%$ gave poor response).

The third one concerning indications, methods, and effectiveness of CPR, most of them had sound knowledge (in terms of scores rewarded, $>40.6 \%$ scored with excellent grade, $26.4 \%$ good and $34 \%$ gave poor response) [Table/Fig-2]. 
Jalpakunvarba Prabhatsinh Chauhan et.al. Cardiopulmonary resuscitation knowledge among physiotherapy students in Ahmadabad.

[Table/Fig-1]: Percentage of responders to the general statements regarding the importance of CPR in clinical practice

\begin{tabular}{|c|c|c|c|c|}
\hline Statement no. & Statement & Yes & No & Don't know \\
\hline 1. & Imprtance of CPR & 94.76 & 4.18 & 1.04 \\
\hline 2. & $\begin{array}{l}\text { Correct CPR } \\
\text { procedure }\end{array}$ & 96.85 & 0.52 & 2.61 \\
\hline 3. & Basic emergency & 95.81 & 1.57 & 2.61 \\
\hline 4. & Participate in CPR & 94.24 & 2.09 & 3.66 \\
\hline 5. & $\mathrm{CPR}$ procedure & 13.08 & 76.96 & 9.42 \\
\hline 6. & More of harmful & 6.80 & 79.05 & 14.13 \\
\hline 7. & $\begin{array}{l}\text { Waste of man } \\
\text { power }\end{array}$ & 4.71 & 92.67 & 2.61 \\
\hline 8. & $\begin{array}{l}\text { Teaching and } \\
\text { mastering CPR }\end{array}$ & 92.67 & 2.61 & 3.66 \\
\hline
\end{tabular}

[Table/Fig-2] Percentage of responders to the statements regarding the indications, methods, and effectiveness of (CPR)

\begin{tabular}{|l|l|l|l|l|}
\hline Statement no. & Statement & True & False & Don't know \\
\hline $\mathbf{1 .}$ & CPR & $94.24 \%$ & $1.57 \%$ & $3.66 \%$ \\
\hline $\mathbf{2 .}$ & Attempted always & $1.57 \%$ & $87.95 \%$ & $3.66 \%$ \\
\hline $\mathbf{3 .}$ & Within 6-7 minutes & $64.39 \%$ & $11.51 \%$ & $23.56 \%$ \\
\hline $\mathbf{4 .}$ & Artificial respiration & $56.02 \%$ & $20.41 \%$ & $23.03 \%$ \\
\hline $\mathbf{5 .}$ & Survive & $67.53 \%$ & $10.99 \%$ & $20.94 \%$ \\
\hline $\mathbf{6 .}$ & Irreversible damage & $68.06 \%$ & $6.28 \%$ & $25.13 \%$ \\
\hline $\mathbf{7 .}$ & No connection to the victim & $53.92 \%$ & $21.98 \%$ & $23.56 \%$ \\
\hline $\mathbf{8 .}$ & Ceases for $>10$ hrs & $68.58 \%$ & $9.94 \%$ & $19.89 \%$ \\
\hline $\mathbf{9 .}$ & Return of spontaneous circulation & $71.20 \%$ & $12.04 \%$ & $16.23 \%$ \\
\hline $\mathbf{1 0}$ & Defibrillator & $83.76 \%$ & $5.75 \%$ & $9.94 \%$ \\
\hline $\mathbf{1 1 .}$ & Compression-only CPR & $49.73 \%$ & $18.32 \%$ & $30.36 \%$ \\
\hline $\mathbf{1 2}$ & Survival rate & $79.05 \%$ & $10.99 \%$ & $8.90 \%$ \\
\hline $\mathbf{1 3}$ & Less effective in children & $48.69 \%$ & $10.99 \%$ & $40.31 \%$ \\
\hline $\mathbf{1 4}$ & Calm and contented & $80.62 \%$ & $6.80 \%$ & $12.56 \%$ \\
\hline $\mathbf{1 5}$ & Misrepresented & $67.01 \%$ & $12.04 \%$ & $20.41 \%$ \\
\hline
\end{tabular}

Only $14.65 \%$ of students rightly answered all the options under the 'purpose of CPR' question as correct [Table/Fig-3].

\section{Purpose of CPR}

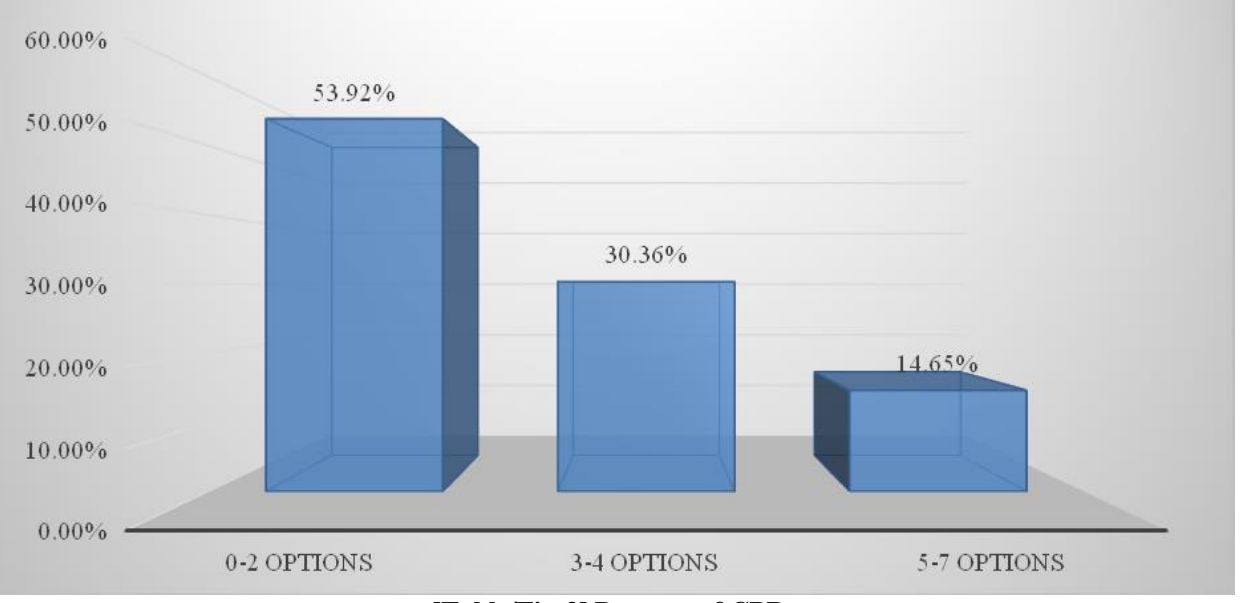

[Table/Fig-3] Purpose of CPR 
When we asked about the 'universal compression to ventilation ratio' in different age groups, only $13.08 \%$ of students partially answered in a correct manner [Table/ Fig-4] and only $38.21 \%$ were aware of the current upgraded order CPR intervention, being $\mathrm{C}-\mathrm{A}-\mathrm{B}$ from previous $\mathrm{A}$ B-C. Regarding the depth of chest compression-only $4.18 \%$ of them answered all the options as correct [Table/Fig-5].

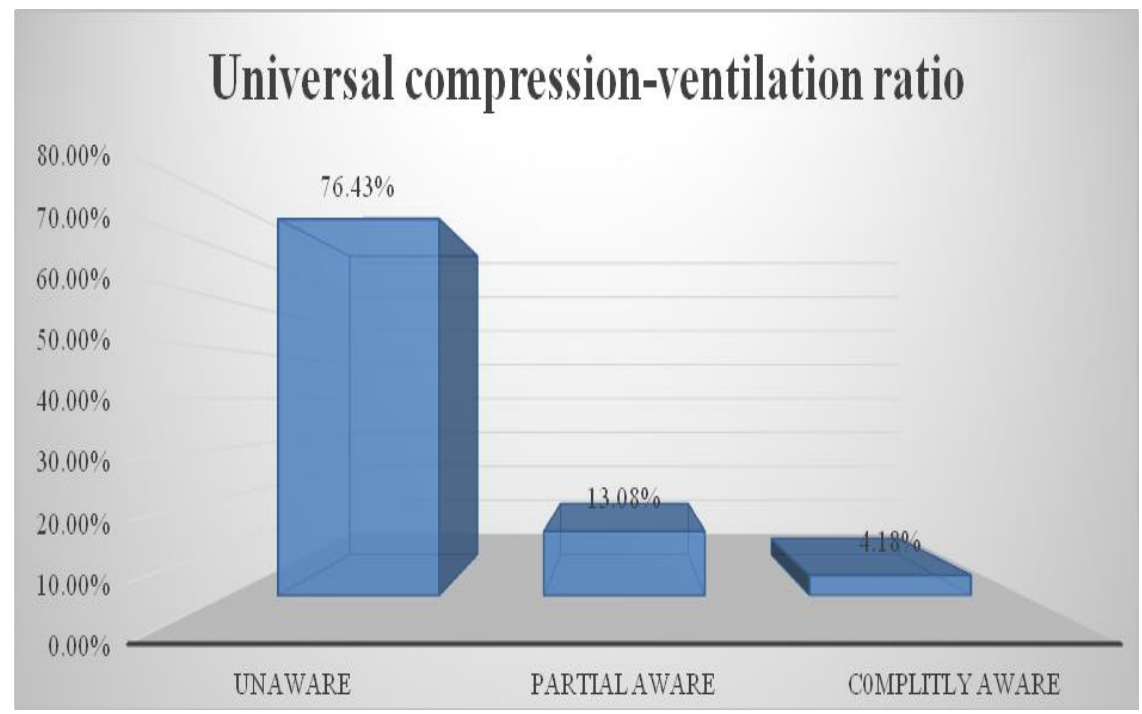

[Table/ Fig-4] Universal compression-ventilation ratio

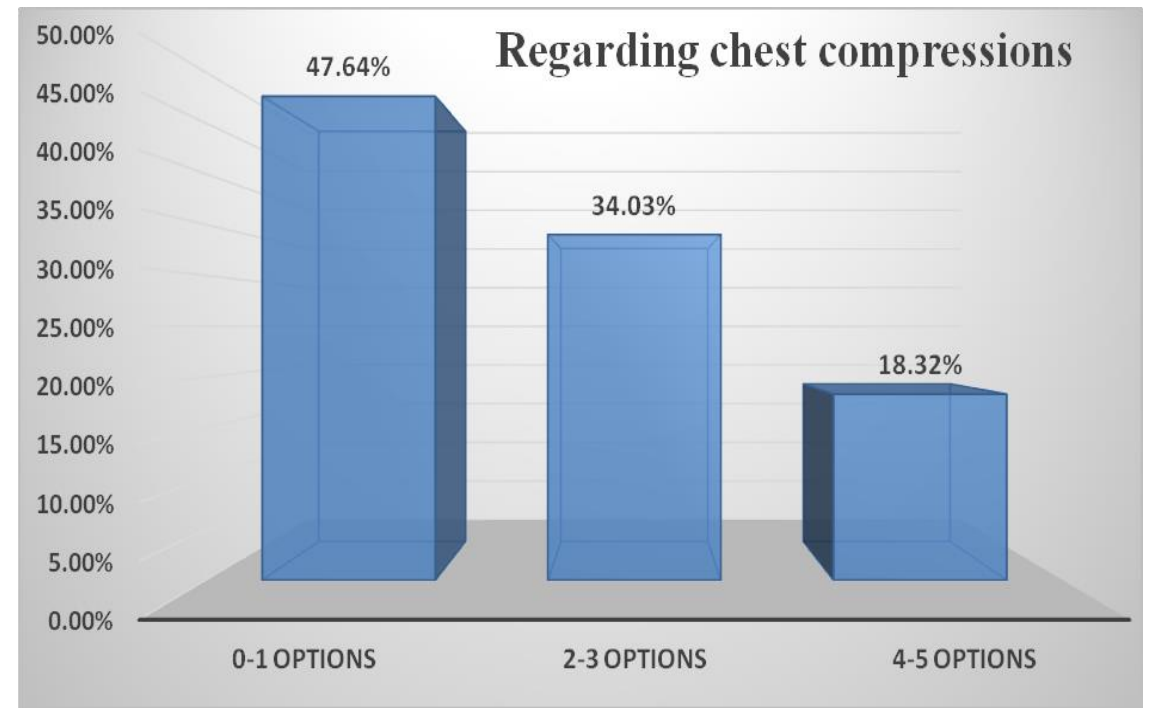

[Table/Fig-5] Regarding chest compressions

\section{DISCUSSION}

The present study evaluated the knowledge of CPR among physiotherapy students in Ahmedabad. Overall, 191 students have participated. Among three categories of a questionnaire survey, students were excellent $(94.74 \%$ reciprocated with positive response) in the first one regarding the importance of CPR where they gave more collective positive response on knowledge and need of CPR. The negatively framed question "CPR was harmful" was intelligently understated by $79.05 \%$ of students. However, $14.13 \%$ of them differed by saying 'did not know"' and $6.80 \%$ has unfortunately accepted the statement. In the second category, questions chosen were about the main goal and accuracy of CPR intervention (in terms of scores rewarded, $18.3 \%$ of them graded as excellent, $39.7 \%$ scored as good and $43 \%$ gave poor response). The third one concerning indications, methods, and effectiveness of CPR, most of them had 
sound knowledge (in terms of scores rewarded, $>40.6 \%$ scored with excellent grade, $29.4 \%$ good and $34 \%$ gave poor response). Only $14.65 \%$ of students rightly answered all the options under the 'purpose of CPR' question as correct. When we asked about the 'universal compression to ventilation ratio' in different age groups, only $13.08 \%$ of students partially answered in a correct manner and only $38.21 \%$ were aware of the current upgraded order CPR intervention, being $\mathrm{C}-\mathrm{A}-\mathrm{B}$ from previous $\mathrm{A}-$ B-C. Regarding the depth of chest compression, only $4.18 \%$ of them answered all the options as correct by using the CPR knowledge questionnaire.[10]

"Cardiorespiratory arrest is the sudden cessation of spontaneous and effective ventilation and systemic perfusion. In the past, whenever the heart stopped working, a patient was considered dead. But we now know that certain interventions, carried out in less than four minutes, would have made the patient survive" [5]. A physiotherapist is expected to have skills and knowledge regarding resuscitation as they work with patients in the hospital as well as out of the hospital. This questionnaire survey demonstrated that CPR knowledge in physiotherapy students was average and needs to be improved.

Meena Kumari K, babu Amberkar $M$, et al,[10] their study shows a similar result as our study and concluded that CPR knowledge in medical students was found to be average. Aroor et al, in a study conducted in South India, reported an overall awareness and knowledge of basic life support (BLS) mean score of 4.16 (SD \pm 1.40 ) of a 10 -maximum indicating a poor knowledge score among nursing, dental and medical individuals including undergraduate, internship and postgraduate groups. However, these knowledge scores are based on a survey about BLS knowledge which is not similar to our survey. In addition, the authors found that age, gender, level of training, the program of study, and previous exposure to BLS were significantly associated with knowledge level [6].
Roshana S, Batajoo KH, Piryani RM, Sharma MW. conducted a study in which the knowledge and experiences of CPR were examined in 61 medical students and found that out of these students only 9 (14.7\%) had taken CPR course while 52 $(85.3 \%)$ students had not attended any such course. Awareness of BLS was present in $66.6 \%$ of students, but skills were found in $18 \%$ only.[12]

Furthermore, healthcare professionals and international studies also reported that trained individuals were more willing and confident to perform bystander CPR [7]. Therefore, trained professionals or students may be able to perform early CPR, initiate resuscitation efforts, and speed up access to prehospital and definitive care. This may lead to increased survival rates and improving patient outcomes. There is much debate about whether resuscitation courses lead to improved life skills. But it redirects to perform resuscitation measures in a logical sequence, thus minimizing mortality and morbidity [4].

In comparison to this study, an American study showed that $9.1 \%$ of individuals did not perform CPR because they believed they would not be able to do it properly [8]. Moreover, trained and more self-confident physiotherapists [7] did answer better questions about CPR compared to those who had not been trained and/or had lower self-confidence. This fact underlines the importance of training in achieving and maintaining a solid theoretical background in CPR. In turn, the latter is crucial since patient survival depends on the time of early defibrillation and the quality of CPR delivery [9], as stressed out in the latest guidelines [3]. In addition, studies concluded that basic and advanced life support skills deteriorate after only 6 months post-training [11]. Therefore, it is imperative to continuously refresh the trainee's knowledge and skills regularly.

Hence, this study was carried out to find out the knowledge of CPR among physiotherapy students in Ahmedabad. 


\section{Limitations Of The Study}

A large study involving UG, interns, PG, and clinicians assessing theoretical, as well as practical knowledge, needs to be done. This questionnaire was more of extracting theoretical knowledge rather than evaluating practical skills of CPR which perhaps could have been more assertive.

\section{CONCLUSION}

The ability to recognize and treat respiratory or cardiac arrest is a basic medical skill that all medical professionals, including medical students and paramedics, are generally expected to possess. As this questionnaire concludes, the CPR knowledge of physiotherapy students is average, these gaps could be improved by conducting many well-designed certified CPR training programs so that students are well aware of these practices and theoretical knowledge.

\section{ACKNOWLEDGMENT}

We thankfully acknowledge the author of a questionnaire for giving permission to use it.

\section{Conflict of Interest: None}

\section{Source of Funding: None}

\section{Ethical Approval: Approved}

\section{REFERENCES}

1. Tripathi HK, Vyas HP. Cardiopulmonary Resuscitation Knowledge/Awareness Among Final Year B. Physiotherapy Students: A Questionnaire-Based Study. National Journal of Integrated Research in Medicine. 2021 May 1;12(3).

2. Vural M, Koşar MF, Kerimoğlu O, Kızkapan F, Kahyaoğlu S, Tuğrul S, İşleyen HB. Cardiopulmonary resuscitation knowledge among nursing students: a questionnaire study. Anatolian Journal of cardiology. $2017 \mathrm{Feb}$;17(2):140.

3. Pepera G, Lilios A, Xanthos T. Knowledge of cardiopulmonary resuscitation among Greek physiotherapists. Monaldi Archives for Chest Disease. 2019 Nov 12;89(3).
4. Avabratha KS, Bhagyalakshmi K, Puranik G, Shenoy KV, Rai BS. A Study of the Knowledge of Resuscitation among Interns. Al Ameen J Med Sci. 2012 Jan;5(2):152-6.

5. Edomwonyi NP, Egbagbe EE. The level of awareness of cardio-pulmonary resuscitation (CPR) amongst radiographers in Nigeria. Journal of Medicine and Biomedical Research. 2006;5(1):29-35.

6. Aroor AR, Saya RP, Attar NR, Saya GK, Ravinanthanan M. Awareness about basic life support and emergency medical services and its associated factors among students in a tertiary care hospital in South India. Journal of emergencies, trauma, and shock. $2014 \mathrm{Jul} ; 7(3): 166$.

7. Abelsson A, Nygårdh A. To enhance the quality of CPR performed by youth layman. International Journal of Emergency Medicine. 2019 Dec;12(1):1-6.

8. Swor R, Khan I, Domeier R, Honeycutt L, Chu K, Compton S. CPR training and CPR performance: do CPR-trained bystanders perform CPR? Academic Emergency Medicine. 2006 Jun;13(6):596-601.

9. Gwinnutt CL, Columb M, Harris R. Outcome after cardiac arrest in adults in UK hospitals: effect of the 1997 guidelines. Resuscitation 2000;47:125-35.

10. Meena Kumari K, babu Amberkar M, Alur S, Bhat PM, Bansal S. Clinical Awareness of Do's and Don'ts of Cardiopulmonary Resuscitation (CPR) Among University Medical Students-A Questionnaire Study. Journal of Clinical and Diagnostic Research: JCDR. 2014 Jul;8(7):MC08.

11. Oteir AO, Almhdawi KA, Kanaan SF, Alwidyan MT, Williams B. Cardiopulmonary resuscitation level of knowledge among allied health university students in Jordan: a cross-sectional study. BMJ open. 2019 Nov 1;9(11):e031725.

12. Roshana S, Batajoo KH, Piryani RM, Sharma MW. Basic life support: knowledge and attitude of medical/paramedical professionals. World journal of emergency medicine. 2012;3(2):141.

How to cite this article: Chauhan JP, Patel H. Cardiopulmonary resuscitation knowledge among physiotherapy students in Ahmadabad. Int J Health Sci Res. 2022; 12(3):54-60. DOI: https://doi.org/10.52403/ijhsr.20220308 
Jalpakunvarba Prabhatsinh Chauhan et.al. Cardiopulmonary resuscitation knowledge among physiotherapy students in Ahmadabad.

\section{Appendix}

\section{Cardiopulmonary Resuscitation Knowledge Questionnaire.}

A. General questions to know the importance of cardiopulmonary resuscitation (CPR) in clinical practice.

\begin{tabular}{|c|c|c|c|c|}
\hline 1 & I am aware about importance of CPR in clinical practice & Y & $\mathrm{N}$ & DK \\
\hline 2 & $\begin{array}{l}\text { According to me, knowledge about correct CPR procedure is mandatory to all health care professionals and it should } \\
\text { be made compulsory }\end{array}$ & $\mathrm{Y}$ & $\mathrm{N}$ & DK \\
\hline 3 & I believe CPR is a basic emergency need for the betterment of mankind and health status & Y & $\mathrm{N}$ & DK \\
\hline 4 & I would like to participate in CPR awareness programs and have lifesaving experience & Y & $\mathrm{N}$ & DK \\
\hline 5 & I believe CPR procedures are arduous, unethical, incorrect and purely inhuman & $\mathrm{Y}$ & $\mathrm{N}$ & DK \\
\hline 6 & Rather than being beneficial, it is more harmful to the patients & $\mathrm{Y}$ & $\mathrm{N}$ & DK \\
\hline 7 & Conducting CPR is simply a waste of man power and time & $\mathrm{Y}$ & $\mathrm{N}$ & DK \\
\hline 8 & Teaching and mastering CPR intervention should be made mandatory to all medical undergraduates & $\mathrm{Y}$ & $\mathrm{N}$ & DK \\
\hline
\end{tabular}

\section{B. The main goal and accuracy of cardiopulmonary resuscitation (CPR) intervention. This study includes both correct and incorrect statements.}

1) The purpose of cardiopulmonary resuscitation (CPR):

1. $\quad$ Restart the heart [ ]

3. Prevent permanent brain damage [ ]

5. Maintain cardiac output to keep vital organs alive [ ]

$2 . \quad$ Restore oxygenated blood to the brain []

4. Delay tissue death [ ]

7. Circulate oxygenated blood []

2) The current order of updated cardiopulmonary resuscitation (CPR) intervention for all age groups except newborns is

\begin{tabular}{l|l|l|l} 
1. & Airway, Breathing, Chest compressions (ABC) & 2. & Chest compressions, Airway, Breathing (CAB) \\
\hline
\end{tabular}

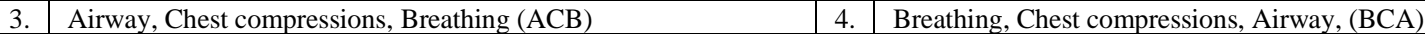

3) The recommended universal compression to ventilation ratio with a compression rate of at least 100 per minute in all groups is

\begin{tabular}{l|l}
$30: 2$ for adults, children and infant if only a single rescuer is present [ ] \\
\hline
\end{tabular}

\begin{tabular}{l|ll}
$15: 2$ in children and infants if at least 2 rescuers are present [ ] \\
\hline 2.
\end{tabular}

3. $3: 1$ in newborns unless a cardiac cause is known [ ]

4) Regarding the chest compression the following procedures are recommended

\begin{tabular}{|l|l|l|l|l}
\hline 1. & Depth in adults and children is about $5 \mathrm{~cm}(2$ inches $)[]$ & 2. & In infants it is $4 \mathrm{~cm}$ (1.5 inches) [ ]
\end{tabular}

3. In adults rescuers should use two hands for the chest compressions []

5. With infants two fingers (index and middle fingers) [

\section{Indications, Methods and Effectiveness of Cardiopulmonary Resuscitation}

\begin{tabular}{|c|c|c|c|c|}
\hline 1 & CPR is an emergency procedure which is attempted in an effort to return life in cardiac arrest & $\mathrm{T}$ & $\mathrm{F}$ & DK \\
\hline 2 & It has to be attempted always inside of a hospital not outside & $\mathrm{T}$ & $\mathrm{F}$ & DK \\
\hline 3 & CPR is generally only effective if performed within $6-7$ minutes of the stoppage of blood flow to vital organs & $\mathrm{T}$ & F & DK \\
\hline 4 & $\begin{array}{l}\text { Artificial respirations are more appropriate than CPR, if a person is not breathing but has palpable pulse (i.e., } \\
\text { respiratory arrest) }\end{array}$ & $\mathrm{T}$ & $\mathrm{F}$ & $\overline{\mathrm{DK}}$ \\
\hline 5 & On average, $85-90 \%$ of people who receive CPR survive if conducted by experienced personnel & $\mathrm{T}$ & $\mathrm{F}$ & DK \\
\hline 6 & $\begin{array}{l}\text { The brain may sustain damage after blood flow has been stopped for about } 4 \text { mins and irreversible damage after about } \\
7 \text { mins }\end{array}$ & $\mathrm{T}$ & $F$ & $\overline{\mathrm{DK}}$ \\
\hline 7 & $\begin{array}{l}\text { According to the recent survey people with no connection to the victim are more likely to perform CPR than a } \\
\text { member of their family }\end{array}$ & $\mathrm{T}$ & $\mathrm{F}$ & DK \\
\hline 8 & If blood flow ceases for $>10 \mathrm{hrs,} \mathrm{virtually} \mathrm{all} \mathrm{cells} \mathrm{of} \mathrm{the} \mathrm{body} \mathrm{die}$ & $\mathrm{T}$ & $\mathrm{F}$ & DK \\
\hline 9 & CPR is generally continued until the person regains return of spontaneous circulation or is declared dead & $\mathrm{T}$ & F & DK \\
\hline 10 & $\begin{array}{l}\text { Defibrillator is an electrical device used as shock to the heart and needed to restore a viable or "perfusing" heart } \\
\text { rhythm }\end{array}$ & $\mathrm{T}$ & $\mathrm{F}$ & DK \\
\hline 11 & Compression-only CPR by the lay public is recommended to an adult having cardiac arrest out of hospital & $\mathrm{T}$ & $\mathrm{F}$ & DK \\
\hline 12 & $\begin{array}{l}\text { The survival rate is very high if immediate CPR is done followed by defibrillation within 3-5 minutes of sudden } \\
\text { cardiac arrest }\end{array}$ & $\mathrm{T}$ & $\mathrm{F}$ & DK \\
\hline 13 & $\begin{array}{l}\text { Compression-only CPR is less effective in children than in adults, as cardiac arrest in children is more likely to have a } \\
\text { non-cardiac cause }\end{array}$ & $\mathrm{T}$ & $\mathrm{F}$ & DK \\
\hline 14 & It is always better to be calm and contented while conducting CPR rather than look frightened & $\mathrm{T}$ & $\mathrm{F}$ & DK \\
\hline 15 & $\begin{array}{l}\text { CPR is often severely misrepresented in movies and television as being highly effective in resuscitating a person who } \\
\text { is not breathing and has no circulation }\end{array}$ & $\mathrm{T}$ & $\mathrm{F}$ & DK \\
\hline
\end{tabular}

